OPEN ACCESS

Edited by:

Alberto Gonzalez Aguilar,

Instituto Nacional de Neurología y

Neurocirugía (INNN), Mexico

Reviewed by:

An-Chi Tien,

Barrow Neurological Institute (BNI),

United States

Sunit Das,

St. Michael's Hospital,

Toronto, Canada

*Correspondence:

Dimitris G. Placantonakis

dimitris.placantonakis@nyumc.org

${ }^{\dagger}$ Present address:

Mark Bustoros,

Department of Medical Oncology,

Dana-Farber Cancer Institute,

Boston, MA, United States

Specialty section:

This article was submitted

to Neuro-Oncology and

Neurosurgical Oncology,

a section of the journal

Frontiers in Neurology

Received: 09 September 2017

Accepted: 06 April 2018

Published: 24 April 2018

Citation:

Bustoros M, Liechty B, Zagzag D,

Liu C, Shepherd T, Gruber D,

Raphael $B$ and Placantonakis $D G$

(2018) A Rare Case of Composite

Dural Extranodal Marginal

Zone Lymphoma and Chronic

Lymphocytic Leukemia/Small

Lymphocytic Lymphoma.

Front. Neurol. 9:267.

doi: 10.3389/fneur.2018.00267

\section{A Rare Case of Composite Dural Extranodal Marginal Zone Lymphoma and Chronic Lymphocytic Leukemia/ Small Lymphocytic Lymphoma}

\author{
Mark Bustoros ${ }^{1 \dagger}$, Benjamin Liechty2 ${ }^{2}$, David Zagzag 1,2,3,4, Cynthia Liu², Timothy Shepherd ${ }^{5}$, \\ Deborah Gruber ${ }^{3,4,6}$, Bruce Raphael ${ }^{3,7}$ and Dimitris G. Placantonakis ${ }^{1,3,4,8,9 *}$
}

${ }^{1}$ Department of Neurosurgery, NYU School of Medicine, New York, NY, United States, ${ }^{2}$ Department of Pathology, NYU School of Medicine, New York, NY, United States, ${ }^{3}$ Perlmutter Cancer Center, NYU Langone Medical Center, New York, NY, United States, ${ }^{4}$ Brain Tumor Center, NYU Langone Medical Center, New York, NY, United States, ${ }^{5}$ Department of Radiology, NYU School of Medicine, New York, NY, United States, ${ }^{6}$ Department of Neurology, NYU School of Medicine, New York, NY, United States, ${ }^{7}$ Department of Medicine, NYU School of Medicine, New York, NY, United States, ${ }^{8}$ Kimmel Center for Stem Cell Biology, NYU School of Medicine, New York, NY, United States, ${ }^{9}$ Neuroscience Institute, NYU School of Medicine, New York, NY, United States

Background: Primary extranodal marginal zone lymphoma (MZL) of the dura is a rare neoplastic entity in the central nervous system (CNS).

Methods: We used literature searches to identify previously reported cases of primary dural MZL. We also reviewed clinical, pathologic, and radiographic data of an adult patient with concurrent dural MZL and chronic lymphocytic leukemia (CLL)/small lymphocytic lymphoma (SLL).

Results: We identified 104 cases of dural MZL in the literature. None of them presented concurrently with another type of non-Hodgkin lymphoma. This is the first report of composite lymphoma consisting of dural MZL and CLL/SLL in the bone marrow and lymph nodes.

Conclusion: Primary dural MZL is a rare, indolent low-grade CNS lymphoma, with a relatively good prognosis. Its treatment is multidisciplinary and often requires surgical intervention due to brain compression, along with low to moderate doses of radiotherapy and/or systemic chemotherapy.

Keywords: extranodal marginal zone lymphoma, central nervous system lymphoma, dura, chronic lymphocytic leukemia/small lymphocytic lymphoma, composite lymphoma

\section{INTRODUCTION}

Primary central nervous system (CNS) lymphomas account for 3-4\% of all CNS malignancies (1-3). Marginal zone lymphoma (MZL) is a low-grade non-Hodgkin's lymphoma (NHL), which, according to the WHO classification, is subdivided into three types: extranodal (also known as mucosa-associated lymphoid tissue MZL), nodal, and splenic (4). Extranodal MZL is the most common variant. According to recent statistics, it constitutes around $8 \%$ of NHL (5), an increase of $3 \%$ compared with prior estimates (4). Extranodal MZL of the gastrointestinal tract was first described by Isaacson and Wright as an indolent low-grade lymphoma (6). Although the stomach is the most 
common site, extranodal MZL also occurs in the mucosa of other organs, including lung, salivary glands, bladder and lacrimal glands, as well as tissues without mucosa, such as thyroid gland, breast, skin, and less frequently the CNS (7-9).

A small number of cases have been reported on dural MZL, all of which were confined to the meninges with no systemic spread at the time of presentation. In this study, we review the literature on dural MZL and present clinical, pathologic, and radiographic data of an adult male with newly diagnosed primary dural MZL and simultaneous chronic lymphocytic leukemia (CLL)/small lymphocytic lymphoma (SLL). The patient subsequently developed lymph node infiltration by both MZL and SLL lymphomas. This case represents the first report of composite lymphoma consisting of dural MZL and CLL/SLL. Composite lymphoma is a rare phenomenon that is defined as the presence of two distinct types of lymphomas in the same patient (10).

\section{MATERIALS AND METHODS}

\section{Literature Search}

Using PubMed searches, we identified 104 cases of dural MZL worldwide. The case we encountered at our institution is the 105th and the first to present concurrently with CLL/SLL in the bone marrow and peripheral blood investigations.

\section{Flow Cytometry and Immunohistochemistry (IHC)}

Specimens including the patient tumor, peripheral blood, and bone marrow biopsy were submitted for flow cytometry and IHC.

Immunophenotypic markers used in flow cytometry were as follows:

B cells: CD10, CD19, CD20, CD23, kappa, lambda;

T cells: CD2, CD3, CD4, CD5, CD7, CD8;

Myeloid: CD11c, CD13, CD14, CD15, CD33, CD117;

Others: CD103, CD25, CD34, CD36, CD38, CD45, CD56, CD64 FITC, HLA-DR.

The following immunohistochemical stains were performed on the brain specimen:

CD3, CD20, CD21, CD10, CD79a, CD138, Bcl2, Bcl6, MUM-1, Ki-67, in situ hybridization studies for kappa, lambda light chains, and EBER;

Immunohistochemistry on the bone marrow biopsy included staining for CD3, CD20, CD5, CD23 and CyclinD1.

\section{Immunoglobulin (Ig) Gene Rearrangement Analysis}

Heavy chain Ig gene rearrangement studies were performed by polymerase chain reaction (PCR) on genomic DNA extracted from tissue. Specific oligonucleotide primers recognizing framework 2 and 3 and the joining (Jh) regions of the human heavy chain were used. PCR products were then electrophoresed on agarose gels. Kappa light chain Ig gene rearrangement analysis was performed using the Invivoscribe IGK Gene Clonality Assay.

\section{RESULTS}

\section{Case Presentation}

A left-handed 59-year-old male presented at our institution with headaches, imbalance, and a left pronator drift on examination. Brain MRI showed a 6-cm enhancing right temporal mass causing severe brain compression, massive amounts of vasogenic edema and significant right-to-left midline shift (Figure 1A). The mass appeared extra-axial and dural based. The mass also showed diffusion restriction on diffusion-weighted imaging (Figure 1A). $\mathrm{He}$ also had a smaller right frontal convexity dural-based lesion with mild local mass effect on the underlying brain parenchyma (Figure 1A). The MRI indicated diffuse pachymeningeal enhancement, especially over the right hemisphere. Given the size of the lesions, as well as the brain compression and the need for diagnosis, we offered the patient a right frontotemporal craniotomy for resection of the two extra-axial lesions. The differential diagnosis preoperatively included multiple meningiomas, metastatic disease, IgG4 disease, and lymphoma.

Intraoperatively, we found that both masses were densely adherent to the dura. We performed gross total resection of both lesions (Figure 1B). The convexity dura attached to the lesions was excised. The dura along the floor of the right middle fossa, where the large temporal mass was attached, was thoroughly coagulated. We used meticulous microdissection to develop the margins of the temporal tumor from the adjacent temporal lobe. Frozen sections from both lesions came back suggestive of atypical lymphoid tissue generating this tumor. Postoperative MRI confirmed gross total resection of both lesions. The patient was started on steroids postoperatively and was discharged to home 3 days after surgery, with complete resolution of his preoperative symptoms. MRI done 6 weeks later showed no recurrence and dramatic improvement in the surrounding vasogenic edema (Figure 1C).

Pathologic examination of the tumors showed dural infiltration by small-sized lymphocytes (Figures 2A,B). Vague germinal centers were seen, which were colonized by the neoplastic lymphocytes. On flow cytometry and immunohistochemical stains, the neoplastic cells were positive for the B cell markers CD19, CD20, and CD79a (Figures 2C,D) and negative for CD5, CD10 (a marker of germinal center B cells). Tumor cells were $\kappa$ light chain-restricted. CD3 immunostaining (a marker of $\mathrm{T}$ cells) showed few reactive $\mathrm{T}$ cells within the tumors (Figure 2E). CD21 highlighted few residual follicular dendritic meshworks. Staining for Epstein-Barr virus (EBV) was negative. MIB1 (Ki67 ) immunolabeling was overall low (20\%), but high in residual germinal centers (Figure 2F). The findings were diagnostic for extranodal MZL.

Bone marrow biopsy and aspirate showed a scant low-grade B-cell lymphoma that coexpressed the B cell markers CD19 and CD20, as well as the CLL markers CD5 and CD23, but lacked CD10 or CD38. This immunophenotype was consistent with CLL/SLL. The cells were dimly $\kappa$ light chain-restricted, and the population represented about $5 \%$ of overall bone marrow cellularity. Flow cytometry of peripheral blood confirmed the diagnosis. Molecular analysis comparing the dural MZL to the CLL/SLL component in bone marrow and peripheral blood was 


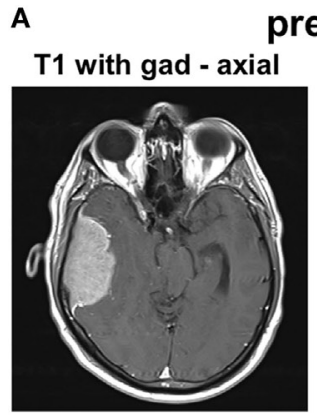

FLAIR - axial

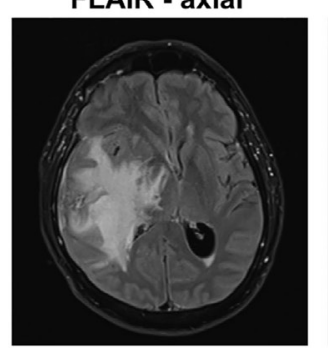

B DWI - axial

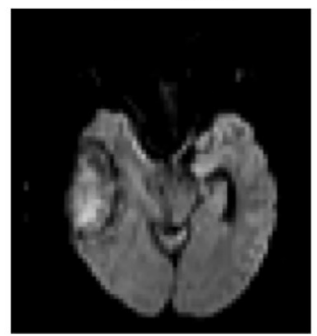

T1 with gad - coronal

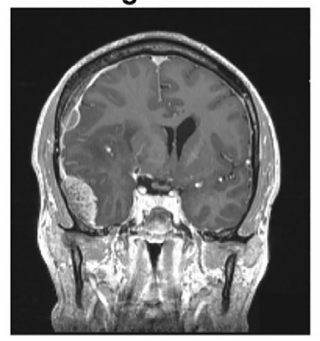

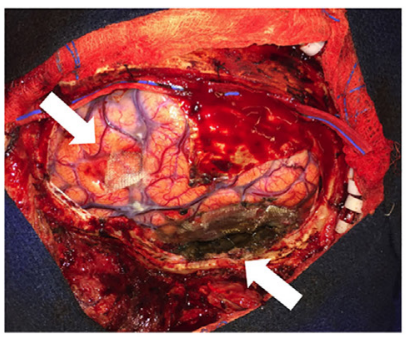

T1 with gad - sagittal

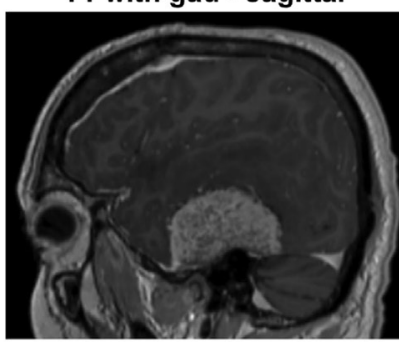

C postop T1 with gad - axial

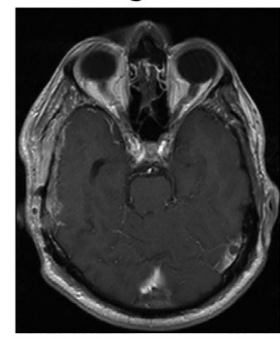

FLAIR - axial

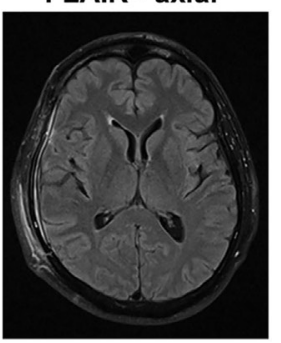

FIGURE 1 | Radiographic findings. (A) Preoperative MRI shows contrast-enhancing extra-axial masses in the right temporal and frontal regions. The temporal mass shows diffusion restriction on diffusion-weighted imaging (DWI) imaging. There was substantial vasogenic edema within a large territory of the right hemisphere on FLAIR images. (B) Intraoperative image shows the areas of the two masses (arrows), after their resection. The image is shown in conjunction with a preoperative sagittal MRI image that highlights the location of the large temporal mass. (C) MRI 6 weeks after surgery shows no recurrence and resolution of the vasogenic edema on FLAIR imaging.

requested. Ig gene rearrangement of the dural tumor detected a $\kappa$ light chain clone of the same size (Jk) as that seen in the peripheral blood. Although these lymphomas were phenotypically different and also presented at different sites, the analysis of Ig gene rearrangement raised the possibility that the two of them shared the same clonal origin.

Starting at approximately 2 months after surgery, the patient received local proton beam radiotherapy (RT) to the right frontal and temporal fields, as well as four cycles of prophylactic intrathecal cytarabine. Multiple lumbar punctures over a 6-month period following surgery showed no evidence of tumor cells. However, 5 months after surgery, he presented with swollen right supraclavicular lymph nodes. CT of the chest and abdomen showed lymph node involvement in the right supraclavicular area and left axilla. Flow cytometry immunophenotyping of supraclavicular lymph node aspirate demonstrated two abnormal B cell populations. The larger one comprised $58 \%$ of all cells, consisted of small to medium-sized cells. It was CD45+ (pan-leukocyte marker), CD19+ (B cell marker), CD20+ (B cell marker), CD5-, CD10- (a marker of germinal center B cells), and surface kappa light chain strongly+, consistent with MZL lymph node. A second smaller cell population represented $6.3 \%$ of all cells and consisted of small cells with the following immunophenotype: CD45+, CD19+, CD20+, CD5+, CD10-, CD23+, CD38-, and surface kappa weakly+. This phenotype indicated the CLL presentation in the lymph node (also known as SLL). These two populations were compatible with the previously diagnosed dural MZL and CLL/SLL, respectively. Moreover, the presence of both MZL and SLL cells in the lymph node confirmed the diagnosis of composite lymphoma. Because both neoplastic processes are considered low-grade, the patient did not receive any additional treatment. On his most recent follow-up, 10 months after surgery, he had no new symptoms, fevers, night sweats, or additional lymph node involvement.

\section{Epidemiological Data}

Analysis of prior literature revealed that dural MZL exhibits a marked female predilection with an approximate female:male ratio of 3:1 (76\% of the cases were females). The reason behind this female predominance is unknown. The median age at presentation was 51 years (range: $28-78)(11,12)$, with the majority being middle-aged females. In all but one case, MZL involved the cranial dura, while in one case it was localized to the thoracic dura (13). Patients presented with a group of symptoms that include: persistent headaches (45\%), seizures (30\%), visual loss (25\%), dizziness (10\%), ataxic gait (10\%), speech deficits (8\%), and hearing deficits (5\%). Most of the cases were immunocompetent, and tests for EBV and human immunodeficiency virus were negative when performed (14). Four cases (4\%) had an underlying autoimmune or infectious disease, including hepatitis $\mathrm{C}$ with immunosuppression after liver transplantation (15), Sjogren's syndrome (16), Graves' disease (17), and multiple sclerosis (14). In two cases, the dural MZL arose after other neoplasms [meningioma (18) and inflammatory breast cancer (19)]. In our case, CLL/SLL was diagnosed concurrently in the bone marrow and peripheral blood. We consider this to be the first reported case of composite lymphoma of dural MZL and CLL. 


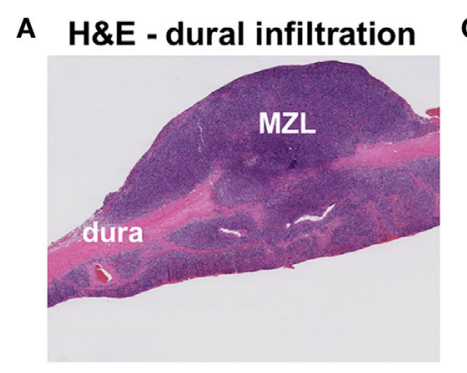

\section{CD20 (B cell marker)}

B

$H \& E$
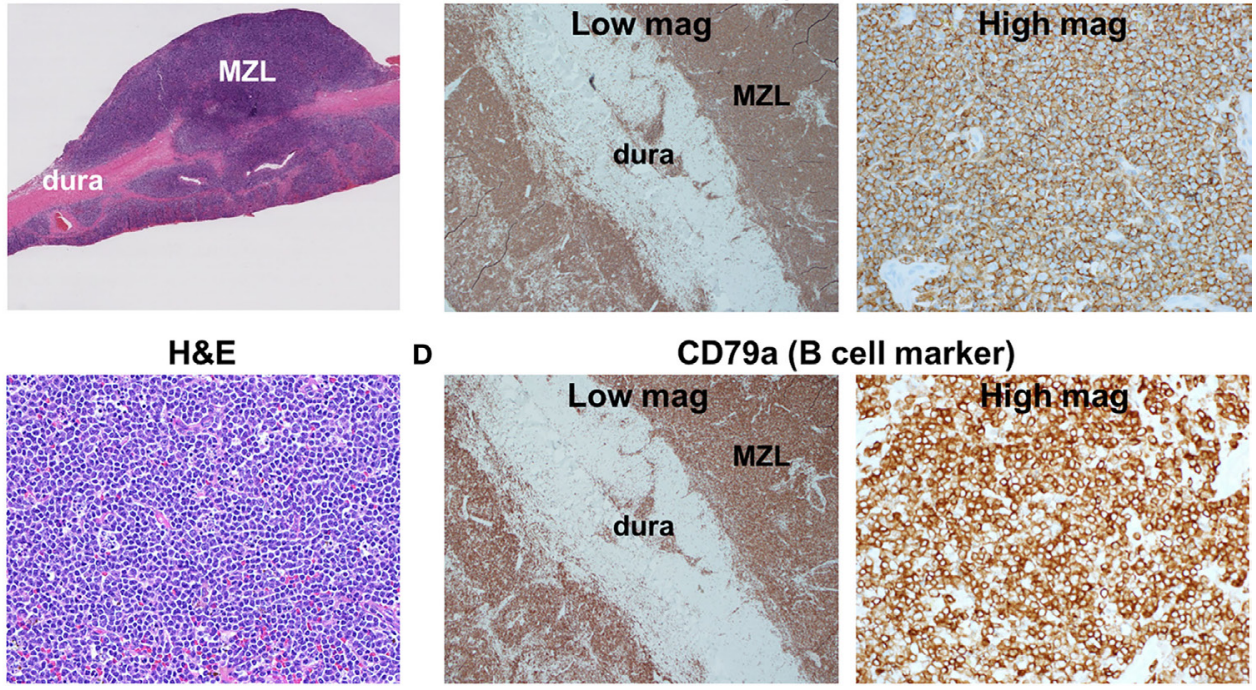

D

\section{CD79a (B cell marker)}
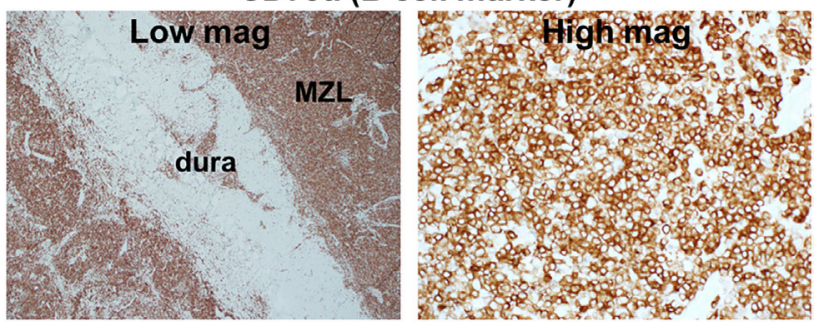

E CD3 (T cell marker)

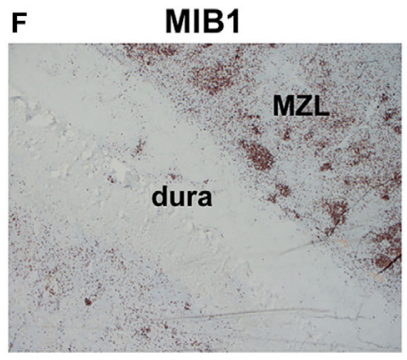

FIGURE 2 | Histologic findings. (A) Low-magnification H\&E staining reveals infiltration of dura by marginal zone lymphoma (MZL) tumor cells. (B) High-magnification H\&E photomicrograph of the neoplasm indicates densely packed small cells. (C,D) Tumor cells are positive for the B cell markers CD20 and CD79a. (E) Scattered reactive $\mathrm{CD} 3+\mathrm{T}$ cells are found within the neoplasm. (F) MIB1 is focally elevated in germinal centers within the neoplasm.

\section{DISCUSSION}

\section{Histopathology}

Marginal zone lymphoma is a low-grade, indolent type of NHL. It arises from marginal zone B cells of secondary lymphoid follicles. It shows a spectrum of cellular constituents, including small lymphocytes, plasmacytoid cells, and plasma cells. Tumor cells show expression of pan-B cell markers (CD19, CD20, and CD79a) and lack the expression of CD5, CD10 (a marker of germinal center B cells). There are frequently a limited number of small normal $\mathrm{CD} 3+$ reactive $\mathrm{T}$ lymphocytes interspersed among the larger tumor cells. Cases with plasmacytic differentiation show restricted Ig light chain with a preponderance of $\kappa$ light chain restriction (Table 1). MIB1 (Ki-67) staining is usually low, ranging from 10 to $30 \%$, which correlates with the indolent nature of this lymphoma. All these markers are essential to distinguish MZL from other types of lymphomas, such as CLL/ SLL (CD5+ and CD23+), mantle cell lymphoma (CyclinD1+, CD5+, CD23-), and follicular lymphoma (CD10+ and Bcl6+). Immunophenotypically, MZL is closely related to Waldenstrom macroglobulinemia (WM), another indolent NHL. Both entities express CD19 and CD20; however, WM mainly arises in the bone marrow and has a higher CD25 expression. Moreover, MYD88 gene mutation is detected in $90 \%$ of WM patients, while being rarely found in MZL (20).

The pathogenesis of dural MZL is not well delineated. In the CNS, there is no MALT tissue. However, it has been hypothesized that meningothelial cells are analogous to epithelial cells at sites where extranodal MZL arises (16,21,40). Meningothelial cells are found throughout the arachnoid membrane and are concentrated in the arachnoid villi adjacent to the dural venous sinuses. Indeed, convexity dura is the most common site of dural MZL (12).

\section{Cytogenetic and Molecular Studies}

Extranodal MZL, especially in the gastric, intestinal, and pulmonary tissues, has a characteristic $\mathrm{t}(11 ; 18)(\mathrm{q} 21 ; \mathrm{q} 21)$ translocation $(54,55)$, where the $3^{\prime}$ end of the MALT1 gene on chromosome 18 is fused to the $5^{\prime}$ portion of API2, located on chromosome 11. This translocation is considered the most common chromosomal aberration in extranodal MZL (55); however, it is not found in the nodal and splenic types $(14,54,55)$. Another common abnormality is the $\mathrm{t}(14 ; 18)(\mathrm{q} 32 ; \mathrm{q} 21)$ translocation, which occurs in 15-20\% of extranodal MZL, especially in nongastrointestinal sites (54). It brings the MALT1 gene under the control of the Ig heavy chain enhancer on chromosome 14 (55, 
TABLE 1 | Summary of cases with central nervous system dural marginal zone lymphoma in chronological order.

\begin{tabular}{|c|c|c|c|c|c|}
\hline No. & Reference & Location & Symptoms & Follow-up (months) & Status \\
\hline 1 & Kumar et al. (21) & Cavernous sinus & Visual defects and numbness & 63 & NED \\
\hline 2 & Kumar et al. (21) & Biparietal & Seizures & 22 & NED \\
\hline 3 & Kumar et al. (21) & Frontal & Seizures and numbness & 7 & NED \\
\hline 4 & Kumar et al. (21) & Tentorial & Headache, visual defects, and numbness & 9 & NED \\
\hline 5 & Kumar et al. (21) & Falx & Seizures & 14 & NED \\
\hline 6 & Kambham et al. (22) & Tentorium & Hearing loss and weakness & 48 & AWD \\
\hline 7 & Kambham et al. (22) & Frontoparietal & Headache, visual defects, and numbness & 6 & AWD \\
\hline 8 & Altundag et al. (23) & Parietal & Seizures & 12 & NED \\
\hline 9 & Itoh et al. (16) & Cerebellopontine & Headache and tinnitus & 24 & NED \\
\hline 10 & Sanjeevi et al. (17) & Cavernous sinus & Headache and visual defects & 15 & NED \\
\hline 11 & Goetz et al. (24) & Frontoparietal & Hemiparesis & 3 & NED \\
\hline 12 & Lehman et al. (25) & Falx & Seizures and speech defects & 8 & AWD \\
\hline 13 & Vazquez et al. (26) & Frontotemporal & Seizures & NA & NA \\
\hline 14 & Bodi et al. (27) & Frontal & Seizures and dizziness & 18 & NED \\
\hline 15 & Benouaich et al. (28) & Frontoparietal & Headache & 24 & NED \\
\hline 16 & Benouaich et al. (28) & Temporal and parietooccipital & Headache & 12 & NED \\
\hline 17 & Lima et al. (29) & Falx and tentorium & Headache and seizures & NA & NA \\
\hline 18 & Garcia-Serra et al. (30) & Temporal and cavernous sinus & Visual defects & 78 & NED \\
\hline 19 & Rottnek et al. (31) & Occipital & Visual defects and seizures & 8 & NED \\
\hline 20 & Kelley et al. (32) & Choroid plexus of lateral ventricle & Headache and seizures & 12 & NED \\
\hline 21 & Tu et al. (14) & Falx & NA & NA & NA \\
\hline 22 & Tu et al. (14) & Frontal & Seizures & 90 & NED \\
\hline 23 & Tu et al. (14) & Frontal & Seizures & 13 & NED \\
\hline 24 & Tu et al. (14) & Posterior fossa & NA & NA & NA \\
\hline 25 & Tu et al. (14) & Middle fossa & NA & NA & NA \\
\hline 26 & Tu et al. (14) & NA & NA & NA & NA \\
\hline 27 & Tu et al. (14) & Subdural & NA & 36 & NED \\
\hline 28 & Tu et al. (14) & Frontotemporal & Headache and dizziness & 21 & NED \\
\hline 29 & Tu et al. (14) & Occipital & Ataxia & 25 & NED \\
\hline 30 & Tu et al. (14) & Parietal & Dysarthria, facial drop, and numbness & NA & NA \\
\hline 31 & Tu et al. (14) & Frontoparietal & Right arm pain & 65 & NED \\
\hline 32 & Tu et al. (14) & Tentorium & Visual defects & 45 & NED \\
\hline 33 & Tu et al. (14) & Falx & Visual defects and gait disturbance & 32 & NED \\
\hline 34 & Tu et al. (14) & Sella and suprasellar cistern & Headache and visual defects & 11 & NED \\
\hline 35 & Tu et al. (14) & Falx and tentorium & Headache and ear pain & 20 & NED \\
\hline 36 & George et al. (33) & Frontal & Behavioral disorder, memory loss, and aphasia & 36 & NED \\
\hline 37 & Abboud et al. (34) & Cerebellopontine & Hearing loss and ataxia & 60 & NED \\
\hline 38 & Assaf et al. (35) & NA & NA & 336 & $\mathrm{RD} /$ death \\
\hline 39 & Iwamoto et al. (36) & Temporoparietal & Headache and facial weakness & 78 & NED \\
\hline 40 & Iwamoto et al. (36) & Frontotemporal & Seizures and visual defects & 84 & NED \\
\hline 41 & Iwamoto et al. (36) & Tentorium and frontoparietal & Headache and dizziness & 53 & NED \\
\hline 42 & Iwamoto et al. (36) & Tentorium & Seizures & 27 & NED \\
\hline 43 & Iwamoto et al. (36) & Frontal and sphenoid sinus & Visual loss and paresthesias & 6 & NED \\
\hline 44 & Iwamoto et al. (36) & Parietal & Seizures & 7 & NED \\
\hline 45 & Iwamoto et al. (36) & Frontal & Headache & 8 & NED \\
\hline 46 & Iwamoto et al. (36) & Frontal & Headaches & 5 & NED \\
\hline 47 & Pavlou et al. (37) & Frontoparietal & Arm weakness, partial seizures, and dysphasia & NA & AWD \\
\hline 48 & Saggioro et al. (38) & Frontotemporoparietal and tentorial & Headaches, facial weakness, and seizures & 12,24 & $\mathrm{RD} /$ death \\
\hline 49 & Jung et al. (39) & Choroid plexus & Seizures and paresis & NA & NA \\
\hline 50 & Ancheta et al. (19) & Temporal and parietooccipital & Aphasia, altered mental status, and seizures & 4 & NED \\
\hline 51 & Bhagavathi et al. (40) & Temporal & Speech defect and numbness & 1 & AWD \\
\hline 52 & Puri et al. (41) & Tentorium & Visual defects and seizures & 48 & NED \\
\hline 53 & Puri et al. (41) & Frontal & Headaches & 30 & NED \\
\hline 54 & Puri et al. (41) & Convexity & Seizures & 32 & NED \\
\hline 55 & Puri et al. (41) & Frontal & Headache, seizures, and visual loss & 36 & NED \\
\hline 56 & Puri et al. (41) & Frontal and sphenoid sinus & Visual loss and paresthesia & 8 & NED \\
\hline 57 & Razaq et al. (12) & Cavernous sinus and optic nerve & Headaches and third cranial nerve palsy & 25 & NED \\
\hline 58 & Razaq et al. (12) & Posterior fossa & Headache and dizziness & 30 & NED \\
\hline 59 & Razaq et al. (12) & Anterior falx & Headache and ataxic gait & 23 & NED \\
\hline 60 & Razaq et al. (12) & Corpus callosum & Headaches and weakness & 48 & NED \\
\hline 61 & Razaq et al. (12) & Temporoparietal & Headaches & 2 & Died* $^{*}$ \\
\hline 62 & Ferguson et al. (42) & Cavernous sinus and optic foramen & Vision loss and exophthalmos & 36 & NED \\
\hline 63 & Gocmen et al. (43) & Frontotemporoparietal & Seizures and dysphasia & 6 & NED \\
\hline 64 & Shaia et al. (44) & Posterior fossa & Dizziness and vomiting & 6 & NED \\
\hline
\end{tabular}


TABLE 1 | Continued

\begin{tabular}{|c|c|c|c|c|c|}
\hline No. & Reference & Location & Symptoms & Follow-up (months) & Status \\
\hline 65 & Matmati et al. (7) & Frontal & Visual defects & 33 & AWD \\
\hline 66 & Reis et al. (45) & Cavernous sinus & Visual defects & NA & NA \\
\hline 67 & Kamoshima et al. (46) & Frontal & Seizures & 36 & NED \\
\hline 68 & Beltran et al. (47) & Parietal and occipital & Headaches & 21 & AWD \\
\hline 69 & Beltran et al. (47) & Frontal & Headaches and seizures & 36 & NED \\
\hline 70 & Beltran et al. (47) & Falx and superior sagittal sinus & Headache, diplopia, and vertigo & 12 & NED \\
\hline 71 & Dey et al. (13) & Spinal (thoracic) & Sensory and motor & 12 & NED \\
\hline 72 & Martin et al. (18) & Parietooccipital & Headache and visual defects & 12 & NED \\
\hline 73 & Sebastian et al. (48) & Falx & Seizures & 9 & AWD \\
\hline 74 & Sebastian et al. (48) & Choroid plexus & Headache and dizziness & 12 & AWD \\
\hline 75 & Choi et al. (9) & Falx and superior sagittal sinus & Headache & 33 & NED \\
\hline 76 & Neidert et al. (49) & Frontoparietal & Facial numbness and seizures & 24 & NED \\
\hline 77 & Okimoto et al. (50) & Frontal and superior sagittal sinus & Headache & 2 & NA \\
\hline 78 & Chen et al. (51) & Posterior fossa & Headache and blurred vision & 12 & AWD \\
\hline \multirow[t]{2}{*}{79} & Kihara et al. (52) & Jugular tubercle & Double vision and hemiparesis & 9 & $\mathrm{RD} / \mathrm{NED}$ \\
\hline & & & & NA & \\
\hline 80 & De la Fuente (53) & Tentorium & Seizures & 145 & NED \\
\hline 81 & De la Fuente (53) & Frontoparietal & Seizures and gait disturbances & 13 & NED \\
\hline 82 & De la Fuente (53) & Parietooccipital & Headache and visual defects & 86 & NED \\
\hline 83 & De la Fuente (53) & Frontal & Headache & 135 & NED \\
\hline 84 & De la Fuente (53) & Tentorium & Facial numbness and tinnitus & 80 & NED \\
\hline 85 & De la Fuente (53) & Temporoparietal & Walking difficulty & 102 & NED \\
\hline 86 & De la Fuente (53) & Occipital & Seizures and visual defects & 67 & NED \\
\hline 87 & De la Fuente (53) & Temporal-frontal & Headache & NA & NA \\
\hline 88 & De la Fuente (53) & Frontoparietal & Seizures & 52 & NED \\
\hline 89 & De la Fuente (53) & Falx & Seizures & NA & NA \\
\hline 90 & De la Fuente (53) & Frontal and parietal & Seizures & 9 & NED \\
\hline 91 & De la Fuente (53) & Temporoparietal & Headache and facial weakness & 209 & NED \\
\hline 92 & De la Fuente (53) & Frontal and orbital & Visual defects & 9 & $\mathrm{RD} / \mathrm{NED}$ \\
\hline 93 & De la Fuente (53) & Temporal-frontal & Headache, seizures, and visual defects & 37 & $\mathrm{RD} / \mathrm{NED}$ \\
\hline 94 & De la Fuente (53) & Frontal & Headache & 15 & NED \\
\hline 95 & De la Fuente (53) & Cavernous sinus & Facial pain & 20 & $\mathrm{RD} / \mathrm{NED}$ \\
\hline 96 & De la Fuente (53) & Frontal & Seizures & 66 & NED \\
\hline 97 & De la Fuente (53) & Temporal & Seizures & 63 & NED \\
\hline 98 & De la Fuente (53) & Frontal & Seizures & 56 & NED \\
\hline 99 & De la Fuente (53) & Cavernous sinus & Facial numbness & 36 & $\mathrm{RD} / \mathrm{NED}$ \\
\hline 100 & De la Fuente (53) & Temporal & Headache and seizures & 29 & NED \\
\hline 101 & De la Fuente (53) & Suprasellar & Headache & 21 & NED \\
\hline 102 & De la Fuente (53) & Cavernous sinus & Cranial nerve palsy & 10 & NED \\
\hline 103 & De la Fuente (53) & Cerebellopontine & Gait disturbances & 8 & NED \\
\hline 104 & De la Fuente (53) & Cavernous sinus & Cranial nerve palsy & 2 & NED \\
\hline 105 & Present case & Frontotemporal & Headaches, imbalance, and pronator drift & 10 & AWD \\
\hline
\end{tabular}

$N E D$, no evidence of disease; $A W D$, alive with the disease; $R D$, relapsed disease; $N A$, not available.

*Death was attributed to a cause other than lymphoma.

56). These two translocations lead to upregulation of BCL10, a protein component of a signaling complex that activates NF- $\kappa \mathrm{B}$ and promotes the growth and survival of B cells. Trisomy of chromosomes $3,7,12$, and 18 can be found in all types of MZL $(14,57)$, but their effect on lymphomagenesis is still unclear $(58)$. In our review of dural MZL, we observed that trisomy 3 is the most common chromosomal aberration $(14,59)$, followed by $t(14 ; 18)(q 32 ; q 21)(40)$. Interestingly, none of the reported cases had $\mathrm{t}(11 ; 18)$.

\section{Imaging Studies}

Dural-based MZL is often misdiagnosed as meningioma on imaging studies, because, both tumors appear as enhancing extra-axial lesions. By contrast, the diffuse large B-cell lymphoma (DLBCL) variant of primary CNS high-grade lymphoma typically localizes to the brain parenchyma. Dural MZL frequently shows a "dural tail" sign on gadolinium-enhanced MRI, a finding classically seen with meningioma (48). It can also induce vasogenic edema, mass effect, and ventricular compression. Although the anatomic location of dural involvement is variable, MZL most commonly arises at the hemispheric convexities, interhemispheric falx, tentorium, and cavernous sinus.

\section{Treatment and Prognosis}

The optimal management of non-gastric extranodal MZL, and particularly dural MZL is not clearly defined. Surgery, chemotherapy, and RT alone or in combination have been used (60). MZL is indolent in nature and thus has a favorable prognosis. Treatment paradigms for dural MZL have varied (Table 2), probably due to the paucity of cases compared with the gastric and the other extranodal sites. 
All patients in our review underwent some form of surgical intervention, either biopsy to obtain tissue and establish diagnosis or resection of the tumor. The resection was complete in many cases; however, partial resection was done in some cases due to neuroanatomic constraints. RT has been shown to significantly prolong overall survival (OS) in both gastric and non-gastric extranodal MZL and was used in $70 \%$ of the dural MZL patients (61). Chemotherapy was also utilized in the management of $35 \%$ of the cases, where methotrexate was the most commonly used agent, either alone or as part of combinatorial therapy (41). Rituximab, a monoclonal antibody against CD20, has also been frequently used in treating dural MZL. It has shown significant activity and tolerability in both gastric and non-gastric extranodal MZL (62). Most of the patients (64\%) were treated with two modalities including resection and RT (72\%); resection and chemotherapy $(17 \%)$ or RT plus chemotherapy (11\%). On the other hand, $27 \%$ were treated with a single modality like resection (44\%), RT (37\%), or chemotherapy (19\%) alone. Finally, only $9 \%$ of patients are treated with all three modalities combined.

Dural MZL has an excellent prognosis. In the 105 patients we reviewed, the median follow-up time was 23 months (range 1-336 months). There was disease recurrence in 12 cases: 4 were at the same site $(13,14,38,52)$, while another 4 , including this case, were extracranial and with no evidence of CNS involvement $(7,35,41)$. The information of the other four relapsed cases was unavailable. The median and average time to relapse was 12 and 40 months, respectively. However, the majority of patients achieved complete remission on further follow-up. Three patients expired, either due to toxicity from the treatment or due to causes other than MZL. One of the cases was diagnosed with a recurrence and died from pneumonia and sepsis secondary to adjuvant therapy (38), while the other two cases succumbed after 2 and 6 months of treatment, respectively. Their death was attributed to causes other than lymphoma $(12,35)$.

A study on non-gastric MZL, which did not include the dural variant, reported that the 5 -year OS and progression-free survival (PFS) were 90 and 60\%, respectively (60). Our analysis of previous published dural MZL cases $(n=93)$ showed that the 5-year OS and PFS were 96.7 and 81.2\%, respectively (Figure 3),

TABLE 2 | Phenotypic and cytogenetic markers in cases with dural marginal zone lymphoma.

\begin{tabular}{lcc}
\hline Feature & Positive & Negative \\
CD19/CD20 & $105 / 105(100 \%)$ & - \\
CD79a & $21 / 21(100 \%)$ & - \\
CD5 & - & $59 / 59(100 \%)$ \\
CD3 & $3 / 29(10 \%)$ & $26 / 29(90 \%)$ \\
CD10 & - & $22 / 22(100 \%)$ \\
CD23 & $5 / 31(16 \%)$ & $26 / 31(84 \%)$ \\
Bcl2 & $19 / 21(90 \%)$ & $2 / 21(10 \%)$ \\
CyclinD1 & - & $33 / 33(100 \%)$ \\
CD43 & $9 / 13(69 \%)$ & $4 / 13(31 \%)$ \\
IgL $\kappa$ & $32 / 42(76 \%)$ & - \\
IgL $\lambda$ & $10 / 42(24 \%)$ & - \\
IgG4 & $7 / 21(33 \%)$ & $14 / 21(67 \%)$ \\
Trisomy 3 & $8 / 17(47 \%)$ & - \\
IgH-MALT1 & $1 / 17(6 \%)$ & -
\end{tabular}

suggesting a better prognosis compared with extranodal MZL in other tissues.

\section{Comparison With Other Lymphomas}

High-grade DLBCL of brain parenchyma is the most common type of primary CNS lymphomas, followed by Burkitt lymphoma (63). Low-grade CNS lymphomas are much less common and are associated with a better prognosis compared with DLBCL. Dural MZL is the most common type of low-grade CNS lymphoma. It occurs in immune-competent patients, and middle-aged females are predominantly affected, in contrast to the immunocompromised state and male predilection seen in CNS DLBCL (14). Most of the large studies on non-gastric MZL $(55,58,60)$ did not include dural-based tumors, likely due to the rarity of such cases. Interestingly, dural MZL was not associated with an infectious etiology like the stomach, intestine, ocular adnexa, and skin extranodal MZL $(58,64)$. Moreover, only $5 \%$ of the dural cases were associated with chronic inflammatory or autoimmune conditions.

\section{Composite Lymphoma}

The case we encountered is unique in its presentation as a composite lymphoma. When two distinct types of lymphomas occur in the same patient, the disease state is termed composite lymphoma. This term was introduced in 1954 by Muller-Hermelink et al. (65) and then refined by Kim et al. (66). Composite lymphomas can be composed of a Hodgkin's lymphoma and an NHL, or two distinct NHL tumors. It may occur in one lymph node or multiple sites in one patient. There can be sharp or diffuse borders or even partial mixtures of infiltrates of various lymphoma types if they occur at the same site. Most of the reported cases of composite NHLs were mantle cell or follicular cell lymphomas associated with CLL or DLBCL $(10,66,67)$. In most reported cases, the two lymphomas were not clonally related. However, in a few cases, Ig gene rearrangement analysis suggested a common clonal origin of two morphologically distinct types $(10,67)$, as occurred in this case. With advances in next-generation sequencing and molecular pathology, the question of a common origin in composite lymphoma can be definitively addressed in the future.

The case we present here is the first report of composite lymphoma consisting of dural MZL and CLL/SLL. The two

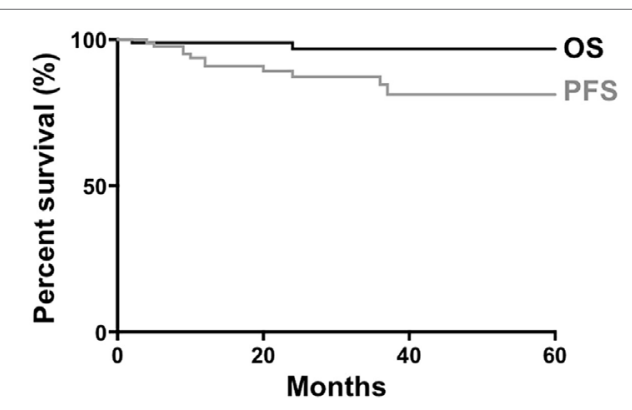

FIGURE 3 | Survival of patients with dural marginal zone lymphoma. Data from 93 patients were available for generation of curves for overall survival (OS) and progression-free survival (PFS). 
components initially presented at different sites, but then concurrently invaded systemic lymph nodes.

\section{CONCLUSION}

Primary dural extranodal MZL is a low-grade NHL. Appropriate pathology and immunophenotyping by IHC and flow cytometry are essential for establishing the diagnosis and distinguishing this neoplasm from otherlymphomas or primarybrain tumors. Combinations of surgical resection, RT, and chemotherapy are effective in producing

\section{REFERENCES}

1. Herman TS, Hammond N, Jones SE, Butler JJ, Byrne GE Jr, Mckelvey EM. Involvement of the central nervous system by non-Hodgkin's lymphoma: the Southwest Oncology Group experience. Cancer (1979) 43:390-7. doi:10.1002/1097-0142(197901)43:1<390::AID-CNCR2820430155>3.0.CO;2-U

2. Ferreri AJ, Marturano E. Primary CNS lymphoma. Best Pract Res Clin Haematol (2012) 25:119-30. doi:10.1016/j.beha.2011.12.001

3. Ostrom QT, Gittleman H, Fulop J, Liu M, Blanda R, Kromer C, et al. CBTRUS statistical report: primary brain and central nervous system tumors diagnosed in the United States in 2008-2012. Neuro Oncol (2015) 17(Suppl 4):iv1-62. doi:10.1093/neuonc/nov189

4. Jakic-Razumovic J, Aurer I. The World Health Organization classification of lymphomas. Croat Med J (2002) 43:527-34.

5. Vannata B, Stathis A, Zucca E. Management of the marginal zone lymphomas. In: Evens MA, Blum AK, editors. Non-Hodgkin Lymphoma: Pathology, Imaging, and Current Therapy. Cham: Springer International Publishing (2015). p. 227-49.

6. Isaacson $\mathrm{P}$, Wright $\mathrm{DH}$. Malignant lymphoma of mucosa-associated lymphoid tissue. A distinctive type of B-cell lymphoma. Cancer (1983) 52:1410-6. doi:10.1002/1097-0142(19831015)52:8<1410::AID-CNCR2820520813> 3.0.CO;2-3

7. Matmati K, Matmati N, Hannun YA, Rumboldt Z, Patel S, Lazarchick J, et al. Dural MALT lymphoma with disseminated disease. Hematol Rep (2010) 2:e10. doi:10.4081/hr.2010.e10

8. Dreyling M, Thieblemont C, Gallamini A, Arcaini L, Campo E, Hermine O, et al. ESMO Consensus conferences: guidelines on malignant lymphoma. Part 2: marginal zone lymphoma, mantle cell lymphoma, peripheral T-cell lymphoma. Ann Oncol (2013) 24:857-77. doi:10.1093/annonc/mds643

9. Choi JY, Chung JH, Park YJ, Jung GY, Yoon TW, Kim YJ, et al. Extranodal marginal zone b-cell lymphoma of mucosa-associated tissue type involving the dura. Cancer Res Treat (2015) 48(2):859-63. doi:10.4143/crt.2014.334

10. Küppers R, Dührsen U, Hansmann M-L. Pathogenesis, diagnosis, and treatment of composite lymphomas. Lancet Oncol (2014) 15:e435-46. doi:10.1016/ S1470-2045(14)70153-6

11. Park I, Huh J, Kim JH, Lee SW, Ryu MH, Kang YK. Primary central nervous system marginal zone B-cell lymphoma of the basal ganglia mimicking low-grade glioma: a case report and review of the literature. Clin Lymphoma Myeloma (2008) 8:305-8. doi:10.3816/CLM.2008.n.043

12. Razaq W, Goel A, Amin A, Grossbard ML. Primary central nervous system mucosa-associated lymphoid tissue lymphoma: case report and literature review. Clin Lymphoma Myeloma (2009) 9:E5-9. doi:10.3816/CLM.2009.n.052

13. Dey M, Daniel S, Wong RH, Smith SM, Yamini B. Marginal zone lymphoma of the thoracic dura causing spinal cord compression. J Clin Neurosci (2013) 20:171-3. doi:10.1016/j.jocn.2012.01.042

14. Tu PH, Giannini C, Judkins AR, Schwalb JM, Burack R, O’neill BP, et al. Clinicopathologic and genetic profile of intracranial marginal zone lymphoma: a primary low-grade CNS lymphoma that mimics meningioma. J Clin Oncol (2005) 23:5718-27. doi:10.1200/JCO.2005.17.624

15. Estevez M, Chu C, Pless M. Small B-cell lymphoma presenting as diffuse dural thickening with cranial neuropathies. J Neurooncol (2002) 59:243-7. doi:10.1023/A:1019913611512

16. Itoh T, Shimizu M, Kitami K, Kamata K, Mitsumori K, Fujita M, et al. Primary extranodal marginal zone B-cell lymphoma of the mucosa- complete remission in most cases. Cases of composite lymphoma, where the dural MZL spreads concurrently with another lymphoma, require monitoring of both neoplastic processes.

\section{AUTHOR CONTRIBUTIONS}

MB and DP conceived the study, collected data, and wrote the manuscript. BL, DZ, and CL provided pathology data and helped write the manuscript. TS, DG, and BR provided clinical data and helped write the manuscript.

associated lymphoid tissue type in the CNS. Neuropathology (2001) 21:174-80. doi:10.1046/j.1440-1789.2001.00392.x

17. Sanjeevi A, Krishnan J, Bailey PR, Catlett J. Extranodal marginal zone B-cell lymphoma of malt type involving the cavernous sinus. Leuk Lymphoma (2001) 42:1133-7. doi:10.3109/10428190109097736

18. Martin SE, Khalidi HS, Hattab EM. Marginal zone B-cell lymphoma involving a longstanding fibrous meningioma: an initial manifestation of systemic disease. Hum Pathol (2013) 44:2609-13. doi:10.1016/j.humpath.2013.04.016

19. Ancheta RG, Lewin H, Said J, Hurvitz SA. Primary dural marginal zone lymphoma in a woman with inflammatory breast cancer. J Clin Oncol (2008) 26:326-8. doi:10.1200/JCO.2007.14.0236

20. Ghobrial IM. Are you sure this is Waldenstrom macroglobulinemia? Hematology Am Soc Hematol Educ Program (2012) 2012:586-94. doi:10.1182/ asheducation-2012.1.586

21. Kumar S, Kumar D, Kaldjian EP, Bauserman S, Raffeld M, Jaffe ES. Primary low-grade B-cell lymphoma of the dura: a mucosa associated lymphoid tissue-type lymphoma. Am JSurg Pathol (1997) 21:81-7. doi:10.1097/00000478-199701000-00009

22. Kambham N, Chang Y, Matsushima AY. Primary low-grade B-cell lymphoma of mucosa-associated lymphoid tissue (MALT) arising in dura. Clin Neuropathol (1998) 17:311-7.

23. Altundag MK, Ozisik Y, Yalcin S, Akyol F, Uner A. Primary low grade B-cell lymphoma of the dura in an immunocompetent patient. J Exp Clin Cancer Res (2000) 19:249-51.

24. Goetz P, Lafuente J, Revesz T, Galloway M, Dogan A, Kitchen N. Primary low-grade B-cell lymphoma of mucosa-associated lymphoid tissue of the dura mimicking the presentation of an acute subdural hematoma. Case report and review of the literature. J Neurosurg (2002) 96:611-4. doi:10.3171/jns.2002.96. 3.0611

25. Lehman NL, Horoupian DS, Warnke RA, Sundram UN, Peterson K, Harsh GRT. Dural marginal zone lymphoma with massive amyloid deposition: rare low-grade primary central nervous system B-cell lymphoma. Case report. J Neurosurg (2002) 96:368-72. doi:10.3171/jns.2002.96.2.0368

26. Vazquez A, Portillo E, Guridi J, Zazpe I, Caballero MC, Valenti C. [Primary low-grade non-Hodgkin's B lymphoma mimicking meningioma]. Neurocirugia (Astur) (2002) 13:50-3. doi:10.1016/S1130-1473(02)70653-2

27. Bodi I, Hussain A, Gullan RW, Safa AS. January 2003: 56-year-old female with right frontal tumor of the dura. Brain Pathol (2003) 13(417-418):423.

28. Benouaich A, Delord JP, Danjou M, Richaud J, Urocoste E, Soum F, et al. [Primary dural lymphoma: a report of two cases with review of the literature]. Rev Neurol (Paris) (2003) 159:652-8. doi:RNE-07-2003-159-6-70000-0000-101019-ART67

29. Lima VS, Leite EB, Fonseca RP, Fernandes AS Jr. Patients presenting with CNS lesions. Case 1. Primary low-grade mucosa-associated B-cell lymphoma of the dura. J Clin Oncol (2003) 21:4058-60. doi:10.1200/JCO.2003.12.054

30. Garcia-Serra A, Price Mendenhall N, Hinerman RW, Lynch JW Jr, Braylan RC, Mancuso AA. Management of neurotropic low-grade B-cell lymphoma: report of two cases. Head Neck (2003) 25:972-6. doi:10.1002/hed.10311

31. Rottnek M, Strauchen J, Moore F, Morgello S. Primary dural mucosaassociated lymphoid tissue-type lymphoma: case report and review of the literature. JNeurooncol (2004) 68:19-23. doi:10.1023/B:NEON. 0000024704.70250 .42

32. Kelley TW, Prayson RA, Barnett GH, Stevens GH, Cook JR, Hsi ED. Extranodal marginal zone B-cell lymphoma of mucosa-associated lymphoid 
tissue arising in the lateral ventricle. Leuk Lymphoma (2005) 46:1423-7. doi:10.1080/10428190500205895

33. George AC, Ozsahin M, Janzer R, Agassis S, Meuli R, Baur AS, et al. Primary intracranial dural lymphoma of mucosa-associated lymphoid tissue (MALT) type: report of one case and review of the literature. Bull Cancer (2005) 92:E51-6.

34. Abboud H, Carpentier A, Martin-Duverneuil N, Kujas M, Hoang-Xuan K. MALT lymphoma presenting as a meningioma. J Neurooncol (2005) 75:221. doi:10.1007/s11060-005-1940-2

35. Assaf C, Coupland SE, Hummel M, Jahnke K, Mostafafivar S, Stein H, et al. Relapse of primary extranodal marginal-zone B-cell lymphoma of the dura mater. Lancet Oncol (2005) 6:187-9. doi:10.1016/S1470-2045(05)01771-7

36. Iwamoto FM, Deangelis LM, Abrey LE. Primary dural lymphomas: a clinicopathologic study of treatment and outcome in eight patients. Neurology (2006) 66:1763-5. doi:10.1212/01.wnl.0000218284.23872.eb

37. Pavlou G, Pal D, Bucur S, Chakrabarty A, Van Hille PT. Intracranial non-Hodgkin's MALT lymphoma mimicking a large convexity meningioma. Acta Neurochir (Wien) (2006) 148:791-3; discussion 793. doi:10.1007/ s00701-006-0761-1

38. Saggioro FP, Colli BO, Paixao-Becker AN, De Rezende GG, Santos AC, Neder L. Primary low-grade MALT lymphoma of the dura. Histopathology (2006) 49:323-6. doi:10.1111/j.1365-2559.2006.02433.x

39. Jung TY, Jung S, Lee MC, Lee KH. Extranodal marginal zone B-cell lymphoma mimicking meningioma in lateral ventricle: a case report and possible pathogenesis. J Neurooncol (2006) 80:63-7. doi:10.1007/s11060-006-9153-x

40. Bhagavathi S, Greiner TC, Kazmi SA, Fu K, Sanger WG, Chan WC. Extranodal marginal zone lymphoma of the dura mater with IgH/MALT1 translocation and review of literature. J Hematop (2008) 1:131-7. doi:10.1007/s12308008-0005-9

41. Puri DR, Tereffe W, Yahalom J. Low-dose and limited-volume radiotherapy alone for primary dural marginal zone lymphoma: treatment approach and review of published data. Int J Radiat Oncol Biol Phys (2008) 71:1425-35. doi:10.1016/j.ijrobp.2007.12.007

42. Ferguson SD, Musleh W, Gurbuxani S, Shafizadeh SF, Lesniak MS. Intracranial mucosa-associated lymphoid tissue (MALT) lymphoma. JClin Neurosci (2010) 17:666-9. doi:10.1016/j.jocn.2009.10.001

43. Gocmen S, Gamsizkan M, Onguru O, Sefali M, Erdogan E. Primary dural lymphoma mimicking a subdural hematoma. J Clin Neurosci (2010) 17:380-2. doi:10.1016/j.jocn.2009.02.014

44. Shaia J, Kerr PB, Saini A, Roberti F, Kapil J, Jones R, et al. Mucosa-associated lymphoma tissue of the dura presenting as meningioma. South Med J (2010) 103:950-2. doi:10.1097/SMJ.0b013e3181eb3477

45. Reis F, Schwingel R, Queiroz Lde S, Zanardi Vde A. Primary dural lymphoma: a rare subtype of primary central nervous system lymphoma (PCNSL). Arq Neuropsiquiatr (2011) 69:264-5. doi:10.1590/S0004-282X2011000200025

46. Kamoshima Y, Sawamura Y, Sugiyama T, Yamaguchi S, Houkin K, Kubota K. Primary central nervous system mucosa-associated lymphoid tissue lymphomacase report. Neurol Med Chir (Tokyo) (2011) 51:527-30. doi:10.2176/nmc.51.527

47. Beltran BE, Kuritzky B, Quinones P, Morales D, Alva JC, Lu G, et al. Extranodal marginal zone lymphoma of the cranial dura mater: report of three cases and systematic review of the literature. Leuk Lymphoma (2013) 54:2306-9. doi:10 $.3109 / 10428194.2013 .771399$

48. Sebastian C, Vela AC, Figueroa R, Marin MA, Alfaro J. Primary intracranial mucosa-associated lymphoid tissue lymphoma. A report of two cases and literature review. Neuroradiol J (2014) 27:425-30. doi:10.15274/NRJ-201410074

49. Neidert MC, Leske H, Burkhardt JK, Rushing EJ, Bozinov O. A 44-year old male with right-sided facial numbness. Dura-associated extranodal marginal zone B cell lymphoma (MALT lymphoma). Brain Pathol (2015) 25:113-4. doi:10.1111/bpa.12234

50. Okimoto RA, Perry A, Rubenstein JL. 77-year-old woman with a duralbased mass. Marginal zone B-cell lymphoma (MZBCL). Brain Pathol (2015) 25:111-2. doi:10.1111/bpa.12233

51. Chen J, Yan Z, Zeng H, Li H, Han A. Teaching neuroimages: primary dural mucosa-associated lymphoid tissue lymphoma. Neurology (2015) 84:e107-8. doi:10.1212/WNL.0000000000001457
52. Kihara K, Sato M, Kado K, Fukuda K, Nakamura T, Yamakami I, et al. [A case of primary dural lymphoma of jugular tubercle mimicking lower clival meningioma]. No Shinkei Geka (2016) 44:391-6. doi:10.11477/mf.1436203297

53. De La Fuente MI, Haggiagi A, Moul A, Young RJ, Sidani C, Markoe A, et al. Marginal zone dural lymphoma: the Memorial Sloan Kettering Cancer Center and University of Miami experiences. Leuk Lymphoma (2017) 58:882-8. doi:10.1080/10428194.2016.1218006

54. Troppan K, Wenzl K, Neumeister P, Deutsch A. Molecular pathogenesis of MALT lymphoma. Gastroenterol Res Pract (2015) 2015:102656. doi:10.1155/2015/102656

55. Raderer M, Kiesewetter B, Ferreri AJ. Clinicopathologic characteristics and treatment of marginal zone lymphoma of mucosa-associated lymphoid tissue (MALT lymphoma). CA Cancer J Clin (2016) 66:152-71. doi:10.3322/ caac. 21330

56. Streubel B, Lamprecht A, Dierlamm J, Cerroni L, Stolte M, Ott G, et al. $\mathrm{T}(14 ; 18)(\mathrm{q} 32 ; \mathrm{q} 21)$ involving IGH and MALT1 is a frequent chromosomal aberration in MALT lymphoma. Blood (2003) 101:2335-9. doi:10.1182/ blood-2002-09-2963

57. Maes B, De Wolf-Peeters C. Marginal zone cell lymphoma - an update on recent advances. Histopathology (2002) 40:117-26. doi:10.1046/j.1365-2559. 2002.01360.x

58. Zucca E, Bertoni F. The spectrum of MALT lymphoma at different sites: biological and therapeutic relevance. Blood (2016) 127:2082-92. doi:10.1182/ blood-2015-12-624304

59. Venkataraman G, Rizzo KA, Chavez JJ, Streubel B, Raffeld M, Jaffe ES, et al. Marginal zone lymphomas involving meningeal dura: possible link to IgG4related diseases. ModPathol(2011)24:355-66. doi:10.1038/modpathol.2010.206

60. Zucca E, Conconi A, Pedrinis E, Cortelazzo S, Motta T, Gospodarowicz MK, et al. Nongastric marginal zone B-cell lymphoma of mucosa-associated lymphoid tissue. Blood (2003) 101:2489-95. doi:10.1182/blood-2002-04-1279

61. Goda JS, Gospodarowicz M, Pintilie M, Wells W, Hodgson DC, Sun A, et al. Long-term outcome in localized extranodal mucosa-associated lymphoid tissue lymphomas treated with radiotherapy. Cancer (2010) 116:3815-24. doi:10.1002/cncr.25226

62. Conconi A, Martinelli G, Thieblemont C, Ferreri AJ, Devizzi L, Peccatori F, et al. Clinical activity of rituximab in extranodal marginal zone B-cell lymphoma of MALT type. Blood (2003) 102:2741-5. doi:10.1182/blood-2002-11-3496

63. Brastianos PK, Batchelor TT. Primary central nervous system lymphoma: overview of current treatment strategies. Hematol Oncol Clin North Am (2012) 26:897-916. doi:10.1016/j.hoc.2012.05.003

64. Thieblemont C, De La Fouchardière A, Coiffier B. Nongastric mucosa-associated lymphoid tissue lymphomas. Clin Lymphoma (2003) 3:212-24. doi:10.3816/CLM.2003.n.002

65. Muller-Hermelink HK, Zettl A, Pfeifer W, Ott G. Pathology of lymphoma progression. Histopathology (2001) 38:285-306. doi:10.1046/j.1365-2559. 2001.01120.x

66. Kim H, Hendrickson R, Dorfman RF. Composite lymphoma. Cancer (1977) 40:959-76.doi:10.1002/1097-0142(197709)40:3<959::AID-CNCR2820400302> 3.0.CO;2-3

67. Hoeller S, Zhou Y, Kanagal-Shamanna R, Xu-Monette ZY, Hoehn D, Bihl M, et al. Composite mantle cell lymphoma and chronic lymphocytic leukemia/ small lymphocytic lymphoma: a clinicopathologic and molecular study. Hum Pathol (2013) 44:110-21. doi:10.1016/j.humpath.2012.04.022

Conflict of Interest Statement: The authors declare that the research was conducted in the absence of any commercial or financial relationships that could be construed as a potential conflict of interest.

Copyright (๑ 2018 Bustoros, Liechty, Zagzag, Liu, Shepherd, Gruber, Raphael and Placantonakis. This is an open-access article distributed under the terms of the Creative Commons Attribution License (CCBY). The use, distribution or reproduction in other forums is permitted, provided the original author(s) and the copyright owner are credited and that the original publication in this journal is cited, in accordance with accepted academic practice. No use, distribution or reproduction is permitted which does not comply with these terms. 